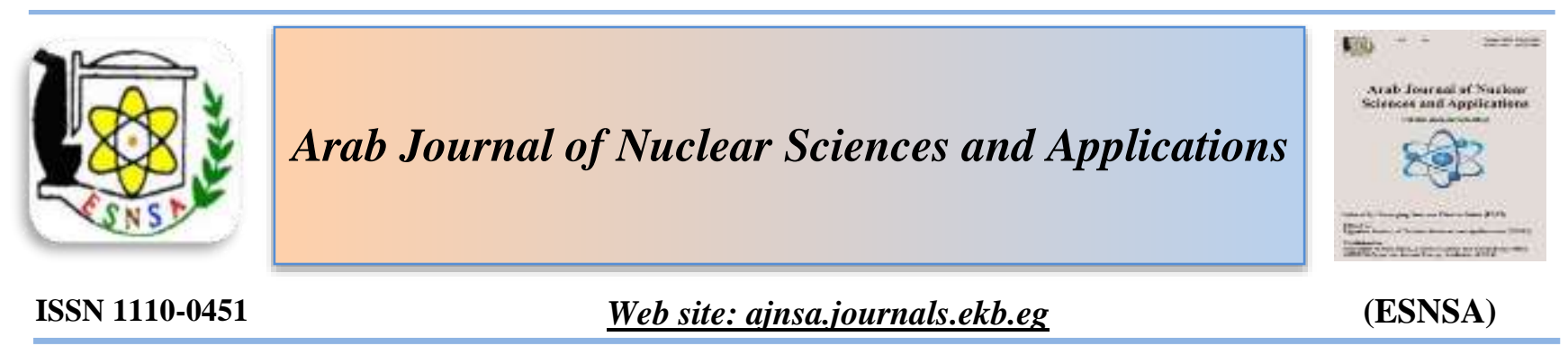

\title{
IAEA activities in support of research reactor and nuclear analytical techniques
}

\author{
N. Pessoa Barradas, A. Migliori, A. Simon, F. Foulon, H. Ben Abdelouahed, I. Swainson, N. Skukan, P. Sladek, \\ R. Padilla Alvarez, S. Charisopoulos, D. Ridikas \\ International Atomic Energy Agency (IAEA), Vienna, Austria
}

\begin{abstract}
Received $8^{\text {th }}$ March 2020 The IAEA provides support to Member States on research reactor and nuclear analytical techniques, Accepted $8^{\text {th }}$ April 2020 including support to strategic and business planning, conducting training workshops, proficiency tests, coordinated research projects and expert missions, editing publications and development of e-learning tools. This paper presents and summarizes some of the recent activities undertaken by the IAEA in this area.
\end{abstract}

\section{Introduction}

Key work areas of the IAEA Physics Section include, among others, the utilization of particle accelerators, applications of research reactors (RRs), nuclear instrumentation, and nuclear fusion research and technology. Activities in support of RR utilization [1] include development and review of strategic and business plans, conducting training workshops, proficiency tests, coordinated research projects and expert missions, development of publications and e-learning tools. It also provides support to Member States in the development of a broad range of nuclear applications, nuclear and other analytical techniques and effective use of nuclear instrumentation, at its Nuclear Science and Instrumentation Laboratory (NSIL) in Seibersdorf, and maintains the IAEA Accelerator Knowledge Portal [2], which includes accelerator research infrastructure databases. This paper presents and summarizes some of the activities undertaken by the IAEA in this area
Key challenges in research reactor utilization Currently, the key challenges in RR utilization can be identified as: decreasing number of operational RRs world-wide, leading to reduced access to RRs but also to increased opportunities for regional and interregional cooperation; ageing of these facilities and of staff, leading to a need for modernization or refurbishment of experimental equipment and devices, and of effective transmission of knowledge to new staff; utilization in many RRs below the full achievable potential; absence of clear utilization purpose and strategy and, in some cases when such a strategy exists, its implementation is constrained by lack of the necessary resources; an increasing number of newcomer countries working on their first RR project. These issues are very often inter-related, and this section is devoted to some of the actions taken by the IAEA to assist Member States in addressing them.

Number of operational research reactors is decreasing

At the date of this Conference, there were 220

Corresponding author: N.Pessoa-Barradas@iaea.org

DOI: $\underline{10.21608 / a j n s a .2020 .92994}$

(C) Scientific Information, Documentation and Publishing Office (SIDPO)-EAEA 
operational RRs [3]. A further 15 RRs were in temporary shutdown, 13 were in extended shutdown, 60 were in permanent shutdown and 67 were under decommissioning. The number of operating RRs peaked in the mid-1970s at 368 and has been decreasing ever since (see Fig. 1). This trend is due to shutdowns in industrialized countries; in developing countries the number of operating RRs has changed little in the last three decades, with a small increase in number of operational RRs since 1995. The IAEA promotes international access to RRs through different schemes.

Utilization as key justification of existing and new research reactors

Ageing of the facilities is an issue that many RRs are facing. More than two thirds of operational RRs are older than 40 years, and more than $40 \%$ are older than 50 years (see Fig. 2), and considerable resources for refurbishment and modernization will be needed to ensure continued operation. At the same time, such investment as well as the continued funding required for operation, has to be justified by a clearly defined mission and utilization programme of the RRs to gather support from the main stakeholders, including the facility's users, the parent organization of the RR and the Government.

At the same time, there are currently over 30 new RR projects world-wide in different stages of planning or implementation [4]. A sound justification of the need for the new research reactor, based on an analysis of the needs for the $\mathrm{R} \& \mathrm{D}$, products and services that the $\mathrm{RR}$ might provide, is the cornerstone for sustainable utilization of the RR in the mid and long term. This analysis must be periodically updated to adapt to any changes in governmental priorities and in the users' needs, which evolve with time.

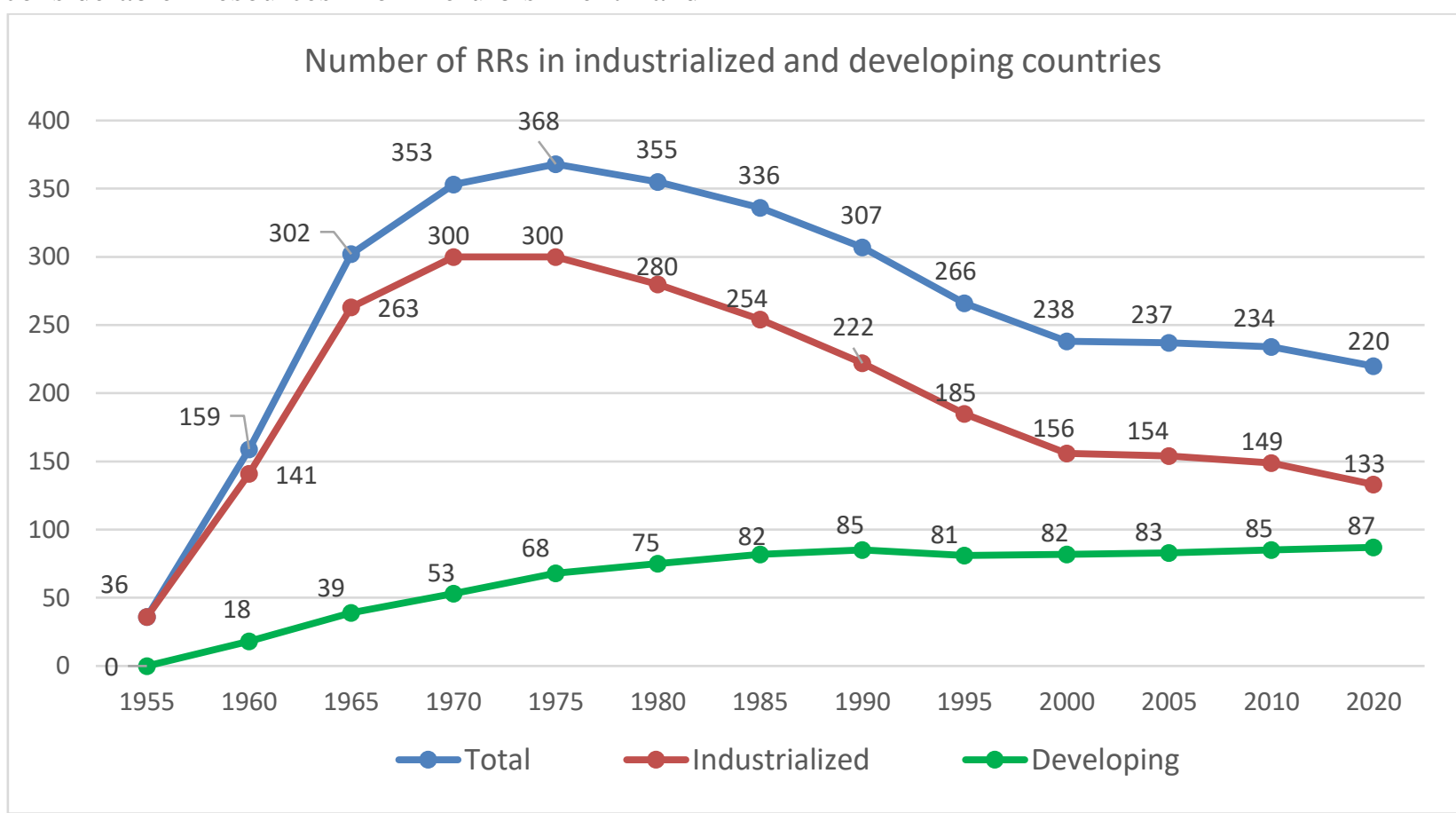

Figure 1: Number of research reactors in industrialized and developing countries. 


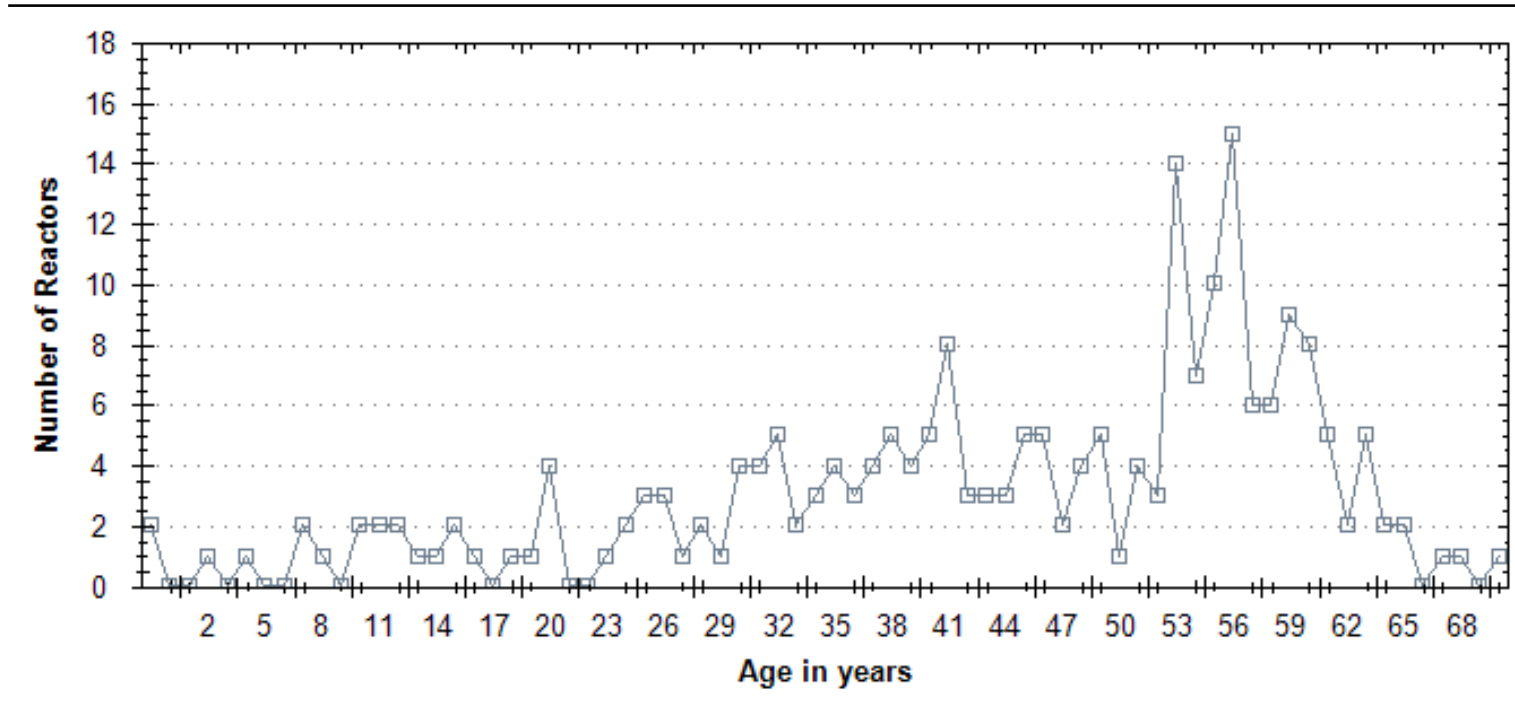

Figure 2: Age distribution of research reactors.

In the absence of any such justification and dynamic adjustment to needs and priorities, a considerable number of existing RRs have not reached their full potential for utilization, and several have been shut down, due to unoptimized utilization and consequent lack of both purpose and justification of continued operation. For new projects, even when a top-down decision has been taken, analysis of stakeholder needs should be conducted and regularly updated, to ensure continued optimized utilization of the RR in the face of changing national priorities, evolving technologies and external circumstances.

\section{Purpose and strategy for utilization}

A strategic plan for utilization is a valuable tool to guide RR operating organizations and reactor managers through a changing environment on the path of sustainable utilization and operation. The IAEA developed different tools to support its Member States in their efforts to develop and implement strategic plans for the utilization of their RRs. The IAEA publication "Strategic Planning for Research Reactors" was published in 2001 [5] and updated in 2017 [6]. It provides strategic planning rationale and methodology, emphasizing the use of strategic planning to increase utilization through diverse applications of RRs [1]. The updated publication includes guidance on strategic planning for new research reactor projects. A clear understanding of stakeholder needs and planning accordingly for utilization are crucial parts of justification of the project in the feasibility study [7].

The IAEA regularly organizes training workshops on strategic and business planning for RRs to disseminate the concepts and development of strategic plan components, share lessons learned, implementation strategies and good practices. An e-learning course on Strategic Planning for National Nuclear Institutions, based on the guidance for RRs, was developed [8]. The IAEA also reviews, on request and with the assistance of international experts, strategic plans submitted by facility managers for that purpose. These reviews are performed against the corresponding IAEA guidance document [6]. In the last five years, the IAEA received, reviewed and provided comments on more than 50 strategic plans for RRs, of which 15 were for new RR projects.

The IAEA recently developed a peer review service named Integrated Research Reactor Utilization Review (IRRUR) [9]. IRRUR aims to provide advice and assistance to Member States in assessing the utilization of RRs and to identify further utilization areas, $R \& D$ and products and services that the $\mathrm{RR}$ can provide, considering opportunities and constraints. In particular, the IRRUR service assists in identifying the gaps and areas of improvement towards effective, efficient, and sustainable utilization of the facility, as well as opportunities to strengthen the user community and to enlarge the utilization stakeholder base. A pilot 
IRRUR mission was conducted to the LENA RR in Pavia, Italy [10], in April 2019. IRRUR was approved as an official IAEA mission in November 2019, available to Member States on request, usually funded by a Technical Cooperation project, or by the facility.

\section{New e-learning tools to support research reactor utilization}

Ageing is an issue that affects not only the RR experimental facilities and other structures, systems and components, but also the staff. With average staff age well over 50 in many reactors, the facilities must develop and implement strategies for effective transmission of knowledge and know-how.

The IAEA has developed, in the last few years, several e-learning courses on RR utilization and other nuclear and related analytical techniques. The objectives have been (a) to promote transmission of knowledge in a context of staff turn-over due to retirement or other causes; (b) to assist development of human capacity building and contribute to the overall sustainability of the techniques; (c) to stimulate high standards of practice in key applications of RRs; (d) to reinforce networking among user communities; and (e) to contribute to outreach and promotion of applications of nuclear analytical techniques.

These e-learning courses are intended to be continuously improved, based on feedback forms included in the tool and on feedback received from users in relevant events, such as training workshops on the courses' subject matter. The following courses are available on the IAEA Cyber Learning Platform for Network Education and Training (CLP4NET) [11]:

\section{Strategic Planning for National Nuclear Institutions}

This course [8] is closely related to the guidance document on Strategic Planning for Research Reactors [6] mentioned above. The concepts therein were extended to be applicable to other facilities such as accelerators facilities for research or radioisotope production, gamma irradiation facilities and analytical laboratories, while continuing to be applicable to RRs. The course was developed with support of a regional IAEA technical cooperation (TC) project RAS0080 'Promoting Self-Reliance and Sustainability of National Nuclear Institutions'.

\section{Neutron Activation Analysis}

The course on Neutron Activation Analysis (NAA) $[12,13]$ is directed at young specialists or beginners without sufficient experience of conducting NAA independently, and it covers all aspects of NAA. The course can also be used by experienced practitioners who want to implement or use another variety of NAA, professional technicians and analysts, users of NAA and other stakeholders who wish to understand the techniques better, professors teaching nuclear sciences and applications \& nuclear analytical techniques, undergraduate and graduate students interested in nuclear sciences and applications and nuclear analytical techniques and facility managers or supervisors who have to make decisions for an NAA system at their neutron source.

The course has 60 modules grouped in seven topical areas and includes lectures, lecture notes, exercises, quizzes videos and case studies (see Fig. 3). It was released in October 2017, and a major update was completed in May 2019, following a workshop organised for the purpose, where users provided feedback on their experience with the course as well as useful suggestions. It has over 210 on-line users from nearly 60 Member States, covering more than $90 \%$ of countries that are engaged in NAA as well as some countries that are planning or considering their first RR project. An off-line version was prepared and over 150 CD ROMs have been distributed.

\section{Neutron imaging}

The course on neutron imaging [14] was developed with similar objectives and directed to the same type of users as the course on NAA. Neutron imaging is, after NAA, the second most common technique found at RRs worldwide [3]. At the time of this Conference, the course was in finalization, to be made available on-line in 
CLP4NET in the second quarter of 2020. The course was developed within the scope of the regional IAEA TC project RER1016 'Enhancing Utilization and Safety of Research Reactors'.

Nuclear Analytical Techniques for Forensic Sciences

Neutron and ion beam nuclear analytical techniques provide unique information in many fields due to their multi-elemental sensitivity, low limits of detection, ability to provide spatially resolved and/or quantitative profiling of trace elements, and, very often, metrological traceability of results. Although these analytical techniques are readily available and routinely applied in research, there is still a considerable gap when it comes to routine forensics applications.

The purpose of this e-learning course [15] is to help to bridge the gap between the practitioners of nuclear analytical techniques and forensic science stakeholder communities. It is directed at forensics specialists who wish to learn more about nuclear analytical techniques, including NAA, and at nuclear techniques practitioners who wish to learn more about the requirements of forensic sciences. This tool is an output of the Coordinated Research Project F11021 "Enhancing Nuclear Analytical Techniques to Meet the Needs of Forensic Sciences".

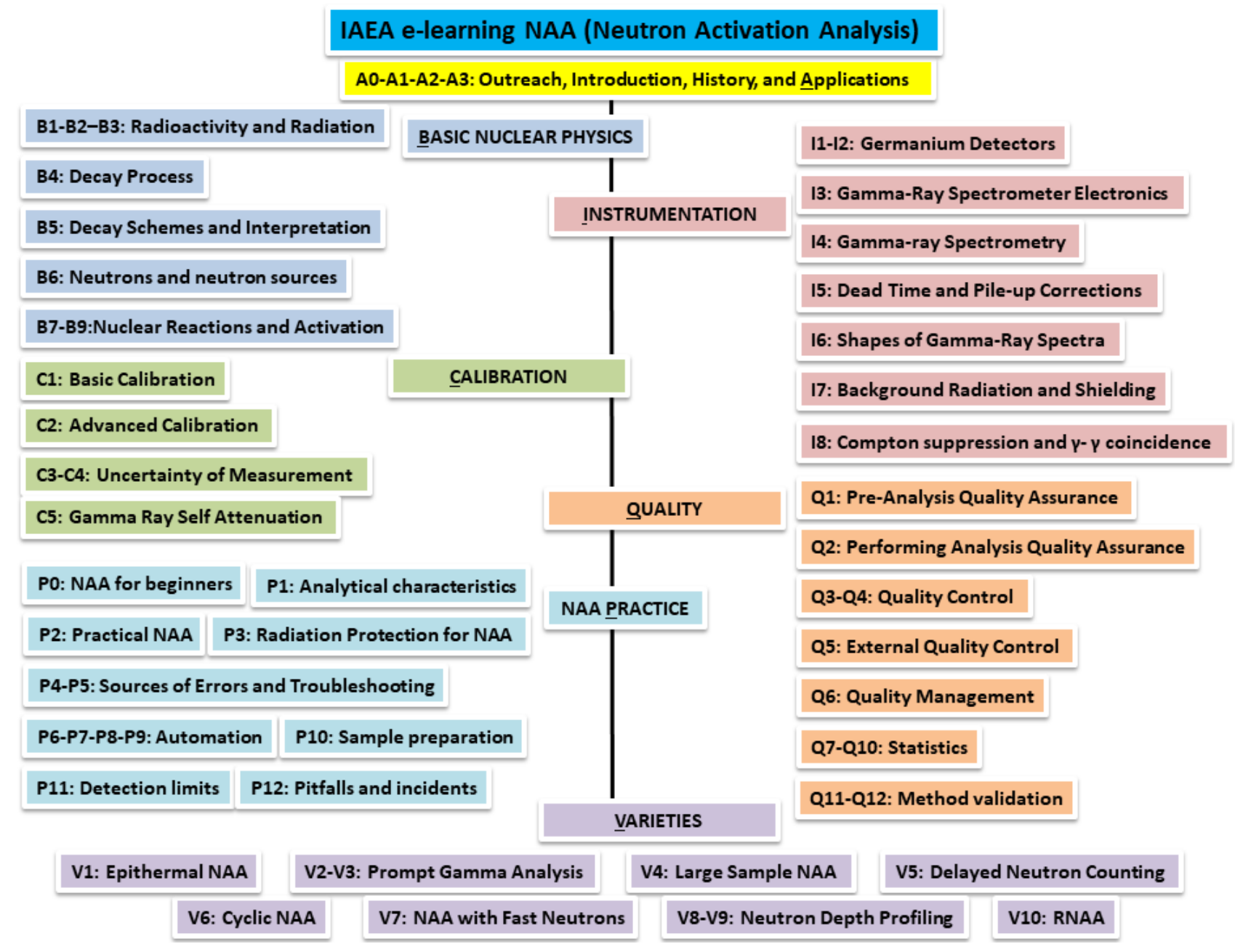

Figure 3: Topical areas and contents of the IAEA e-learning course on NAA. 


\section{Introductory training course for research reactor} personnel

The Introductory training course for research reactor personnel [16] was developed under the scope of TC regional project RLA1012 "Developing a Capacity Building Programme to Ensure Sustainable Operation of Nuclear Research Reactors through Personnel Training", and is offered in both English and Spanish. The course, now available to all Member States, is divided in three main areas: Reactor Theory, Research Reactors, and Operation and Safety of Research Reactors.

The course is primarily directed at technical and scientific personnel of RRs, namely involved in operation, maintenance and safety of RRs. The course can be used by newcomers to a RR facility, including future operators, regulators, technicians, managers, users and other stakeholders, and by personnel already working with a RR or assuming new functions within the facility. The course can also be used by students and other stakeholders of RRs.

\section{Introduction to $X$ ray Emission Spectrometry}

This course [17] aims at introducing the reader to the fundamentals of several $X$ ray spectroscopy techniques. Due to the common need for elemental composition analysis, emphasis is made on Energy Dispersive $\mathrm{X}$ ray Fluorescence, which constitutes an affordable option for IAEA Member States laboratories. This course is addressed to specialists and managers of laboratory facilities willing to incorporate $\mathrm{X}$ ray spectroscopy techniques into their research and services. Managers will benefit from general knowledge on the capabilities, advantages and limitations of the techniques. The infrastructure required for the implementation can be identified, as well as the needs for specialized training and capacity building. Specialists working in applied research and analytical services will learn on the capabilities of the techniques for different applications and analytical tasks.

Introduction to in-situ techniques for radiological characterization of sites

The use of in-situ techniques in environmental monitoring has increased during the last years. However, there is an uneven level of experience and access to such techniques in the IAEA Members States. This course [18] supports Member States in their efforts to develop their infrastructure and technologies for radiological characterization of relevant sites in a timely, safe and cost-effective manner. This course is addressed to different stakeholders involved in environmental impact assessment and remediation: Public or stakeholder groups, educational institutions, junior professionals and graduate level, environmental monitoring laboratory specialists, managers, regulators, environmental remediation companies, and emergency responders.

\section{NAA proficiency testing by interlaboratory comparison}

Since 2010 the IAEA has supported the participation of NAA laboratories in proficiency testing by interlaboratory comparison. Until 2017, around 30 laboratories were supported by the IAEA to participate in the exercises organized by the Wageningen Evaluating Programmes for Analytical Laboratories [19]. In 2018 the IAEA started to organize the exercises through NSIL [20]. In 2018 and 2019 more than 40 laboratories participated, but nearly 10 did not report results in 2019 due to unavailability of the RR [19, 21, 22].

The results are shown in Fig. 4. Significant overall improvement of performance since 2010 is observed. At the same time, many gross errors are still committed, which indicates ineffective QA/QC and continued need for consolidation and improvement of performance.

The IAEA has organized feedback workshops to share good practices and discuss methods for improvement of performance and lessons learned, and in 2019 the section on QA/QC of the e-learning course on NAA was significantly expanded. A publication to provide 
practical guidance on QA/QC in NAA was edited and is expected to be published in 2020 [23].
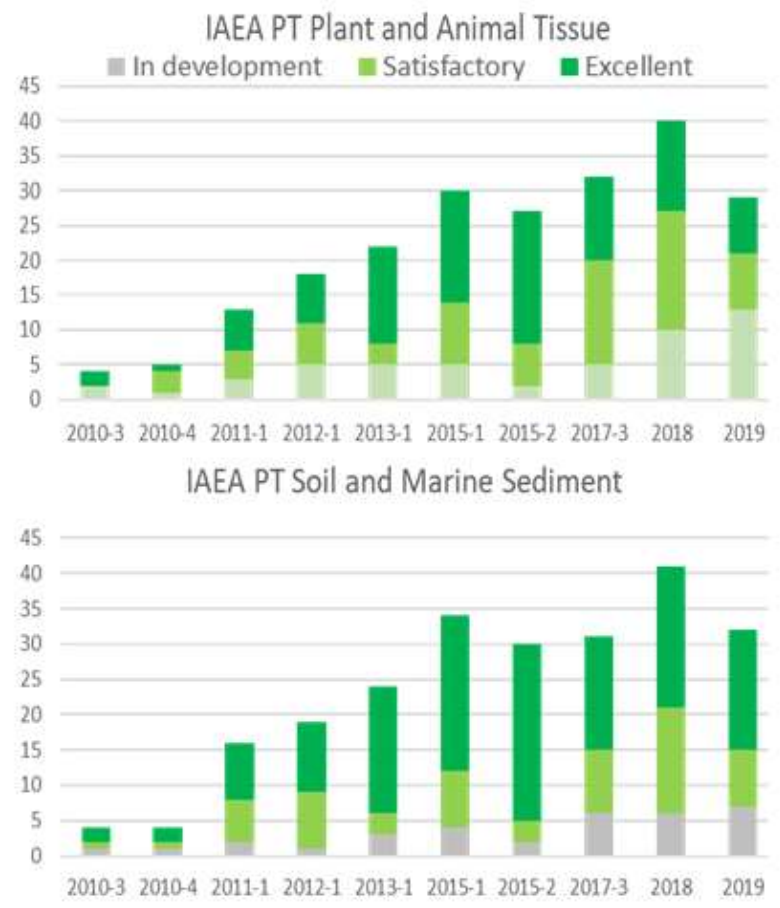

Figure 4: Results of NAA proficiency testing by interlaboratory comparison. The number of laboratories with results considered excellent, satisfactory or in development is shown for each consecutive exercise

\section{Establishment of an IAEA Neutron Science Facility}

NAA and other neutron-based techniques are also carried out with accelerator-based neutron sources, particularly for in-situ applications. Compact deuterium-deuterium (DD) neutron sources that generate $2.5 \mathrm{MeV}$ neutrons and deuterium-tritium (DT) neutron sources that generate $14 \mathrm{MeV}$ neutrons allow rapid and user-friendly elemental analysis. Applications of neutron generators include education and training in neutron science, NAA of various samples and objects, neutron radiography and tomography, radiotracer production for industrial applications, investigations related to security and safeguards applications and testing of neutron sensors and detectors.

The IAEA is developing a state-of-the-art Neutron
Science Facility (NSF) at NSIL, with the purpose to expand its capabilities to support its Member States in capacity building, scientific research and diverse applications using neutrons [24]. The NSF will allow Member States to have access to neutron-based analytical techniques, receive the necessary training and expertise to build their own capacities and will play a leading role in demonstrating the techniques and developing the use of neutron generators. The establishment of the NSF is on-going, with two neutron generators, providing neutrons in the energy range of fission $(2.45 \mathrm{MeV})$ and fusion $(14 \mathrm{MeV})$ and intensities up to $10^{8} \mathrm{n} / \mathrm{s}$. Optimization of the shielding design is under finalization. The radiation monitoring systems has been commissioned. A High Purity Germanium Spectrometer for NAA has been installed and tested. Finally, a dual neutron / X ray imaging system has been installed and tested with $\mathrm{X}$ rays (see Fig. 5).

\section{Summary}

In this paper, the key challenges in RR utilization were discussed, and the IAEA activities to support efficient and sustainable utilization of RRs were presented. In particular, the role of strategic planning to improve all aspects of the utilization and sustainability of existing RRs, as well as the successful and sustainable long-term utilization of new RRs, was stressed.

The newly developed Integrated Research Reactor Utilization Review (IRRUR) mission was presented. It assists Member States in identifying the gaps and areas of improvement in utilization, including $R \& D$ and products and services that RRs can provide, towards effective, efficient, and sustainable utilization of the facility, as well as opportunities to strengthen and enlarge the user community.

The e-learning courses recently developed or updated by the IAEA related to other nuclear analytical techniques and relevant to utilization of RRs were presented. Seven different courses were developed in the past three years, and the Physics Section of 


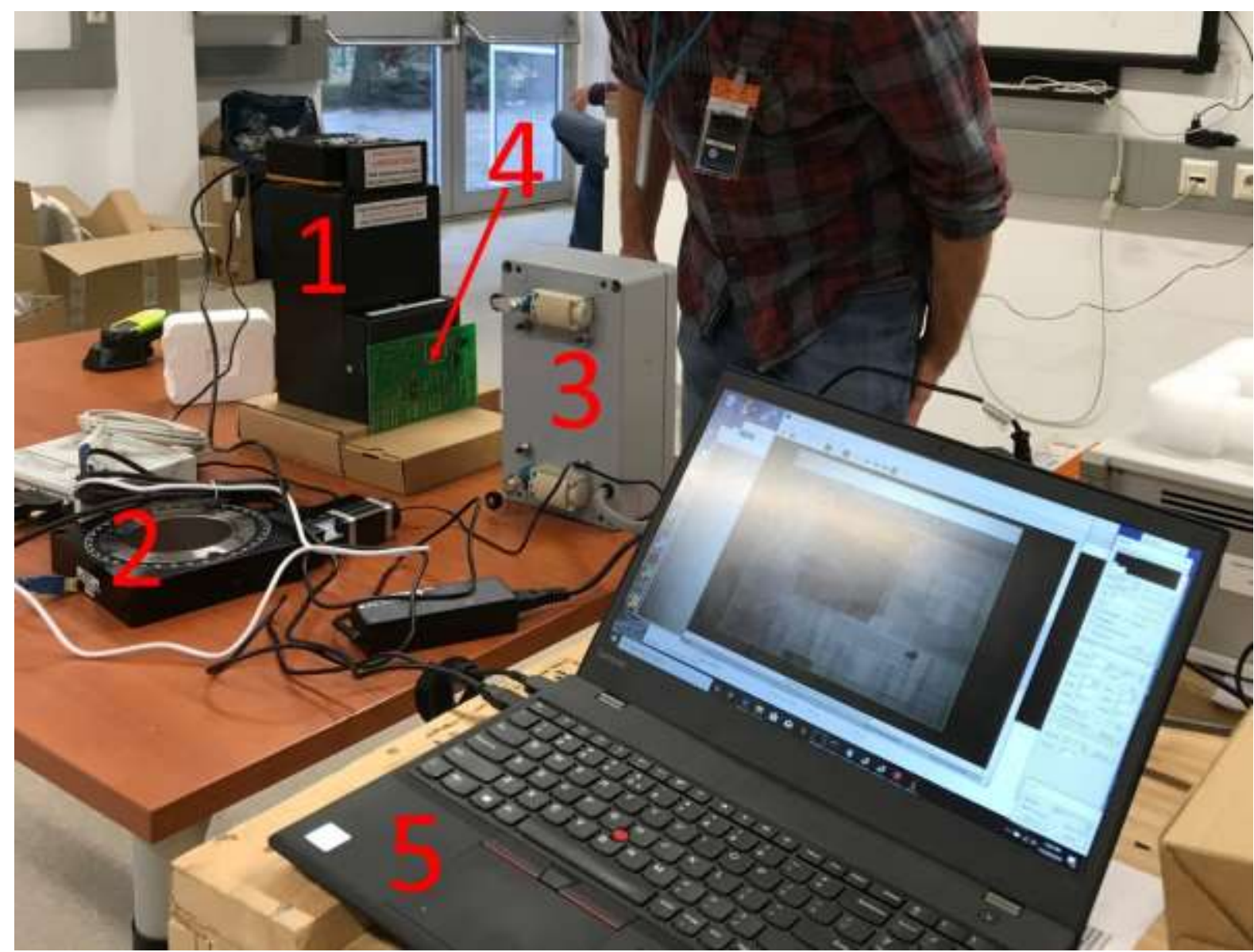

Figure 5: Testing of the dual neutron / $X$ ray imaging system. 1: camera box; 2: rotating stage (not in use in this image); 3: $X$ ray source; 4: sample; 5: computer control.

2-INTERNATIONAL ATOMIC ENERGY AGENCY,

the IAEA is currently developing several other elearning courses to meet Member States needs in capacity building and transmission of knowledge in nuclear sciences and technology.

The status of the IAEA Neutron Science Facility currently being established at its Seibersdorf Nuclear Science and Instrumentation Laboratory was presented. Based on compact DD and DT neutron generators, the facility, among other techniques, will offer NAA, delayed neutron counting and neutron imaging. It will also be available for training purposes and $R \& D$.

\section{References}

1-INTERNATIONAL ATOMIC ENERGY AGENCY, Applications of Research Reactors, IAEA Nuclear Energy Series No. NP-T-5.3, ISBN 978-92-0145010-4 Vienna (2014).
Accelerator Knowledge

Portal, https://nucleus.iaea.org/sites/accelerators

3-INTERNATIONAL ATOMIC ENERGY AGENCY, IAEA Research Reactor Database https://nucleus.iaea.org/RRDB.

4-INTERNATIONAL ATOMIC ENERGY AGENCY, Specific Considerations and Milestones for a Research Reactor Project, IAEA Nuclear Energy Series No. NP-T-5.1, IAEA, Vienna (2012).

5-INTERNATIONAL ATOMIC ENERGY AGENCY, Strategic Planning for Research Reactors - Guidance for Reactor Managers, IAEA-TECDOC-1212, IAEA, Vienna (2001).

6-INTERNATIONAL ATOMIC ENERGY AGENCY, Strategic Planning for Research Reactors, IAEA Nuclear Energy Series No. NG-T-3.16, IAEA, Vienna (2017).

7-INTERNATIONAL ATOMIC ENERGY AGENCY, Feasibility Study Preparation for New Research Reactor Programmes, IAEA Nuclear Energy Series NG-T-3.18, IAEA, Vienna (2018). 
8-INTERNATIONAL ATOMIC ENERGY AGENCY, E-learning course on Strategic Planning for National Nuclear Institutions.

9-INTERNATIONAL ATOMIC ENERGY AGENCY, Integrated Research Reactor Utilization Review (IRRUR), https://www.iaea.org/services/reviewmissions/irrur

10-https://elearning.iaea.org/m2/course/view.php?id=57 0 .

11-Pilot Integrated Research Reactor Utilization Review (IRRUR) Mission to LENA TRIGA Mk II: lessons learned, Andrea Salvini, D. Alloni, M. Prata, S. Manera, M. Giordano, Proc. Int Conf on Research Reactors: Addressing Challenges and Opportunities to Ensure Effectiveness and Sustainability, 25-27 November 2019, Buenos Aires, Argentina.

12-INTERNATIONAL ATOMIC ENERGY AGENCY, Cyber Learning Platform for Network Education and Training (CLP4NET). https://elearning.iaea.org.

13-INTERNATIONAL ATOMIC ENERGY AGENCY, E-learning course on Neutron Activation Analysis. https://elearning.iaea.org/m2/course/view.php?id=48 2.

14-The IAEA e-learning course on Neutron Activation Analysis, N. Pessoa Barradas, P. Bode, S. Landsberger, D. Ridikas, A. Iunikova, Proc. European Research Reactor Conference, RRFM, 1115 March 2018, Munich, Germany. ISBN: 978-9295064-29-4

15-INTERNATIONAL ATOMIC ENERGY AGENCY, E-learning course on Neutron Imaging. https://elearning.iaea.org/m2/course/view.php?id=63 3.

16-INTERNATIONAL ATOMIC ENERGY AGENCY, E-learning course on Nuclear Analytical Techniques for Forensic Sciences.

17-https://elearning.iaea.org/m2/course/view.php?id=58 2.

18-INTERNATIONAL ATOMIC ENERGY AGENCY, E-learning course "Introductory training course for research reactor personnel".

19-https://elearning.iaea.org/m2/enrol/index.php?id=53 1.

20-INTERNATIONAL ATOMIC ENERGY AGENCY,
E-learning course "Introduction to $\mathrm{X}$ ray emission spectrometry"

https://elearning.iaea.org/m2/course/view.php?id=60 7

21-INTERNATIONAL ATOMIC ENERGY AGENCY, E-learning course "Introduction to in-situ techniques for radiological characterization of sites" https://elearning.iaea.org/m2/course/view.php?id=59 3

22-INTERNATIONAL ATOMIC ENERGY AGENCY, Proficiency Testing by Interlaboratory Comparison performed in 2010-2015 for NAA and other analytical techniques, IAEA-TECDOC-1831, IAEA, Vienna (2017).

23-INTERNATIONAL ATOMIC ENERGY AGENCY, Nuclear Science and Instrumentation Laboratory Proficiency Tests, http://www.pt-nsil.com/

24-Proficiency testing by interlaboratory comparison performed in 2010-2017 for Neutron Activation Analysis, N. Pessoa Barradas, P. Bode, D. Ridikas, Proc. European Research Reactor Conference, RRFM, 11-15 March 2018, Munich, Germany. ISBN: 978-92-95064-29-4

25-The world's largest proficiency testing exercise for Neutron Activation Analysis laboratories by interlaboratory comparison: Focus on Europe, A. Migliori, N. Pessoa Barradas, D. Ridikas, A. Katukhov, P. Bode, Proceedings of RRFM 2019, 24 28 March 2019, Swemieh, Jordan. ISBN: 978-9295064-31-7.

26-INTERNATIONAL ATOMIC ENERGY AGENCY, Practical Guide to Quality Assurance and Quality Control in Neutron Activation Analysis, IAEA Technical Report Series, IAEA, Vienna (in editing).

27-IAEA Nuclear Science and Instrumentation Laboratory: Support to IAEA Member States and Recent Developments, F. Foulon, H. Ben Abdelouahed, M. Bogovac, S. Charisopoulos, M. Matos, A. Migliori, R. Padilla-Alvarez, N. Pessoa Barradas, D. Ridikas, A. Simon, N. Skukan, P. Sladek, I. Swainson, EPJ Web of Conferences, 225 (2020) 10005. 